\title{
STUDYING SOME BIOLOGICAL FEATURES OF PEAR CULTIVARS BLOSSOMING IN THE SOUTH OF RUSSIA
}

\author{
Mozhar N. V. \\ Federal State Budgetary Scientific Institution \\ "North Caucasian Federal Research Centre for Horticulture, Viticulture, Wine-making", \\ c. Krasnodar,Russia,e-mail: mozhar49@mail.ru
}

A cultivar suitability to certain environmental conditions can be judged by the terms of plant development phases. The paper studied some biological characteristics of pear cultivars, passage of phenological stages during the growing season, specifics of flowering and their compliance with natural and climatic conditions of cultivation. The following valuable pear cultivars with late flowering terms were allocated: 'Wiliams stavropolskiy', 'Luberskaya', 'Podkumok', 'Velesa', 'Zimnyaya mliyevskaya' and 'Zaporozhskaya' for state and production study, as well as original forms for further use in breeding.

Key words: pear, cultivar, phenology, development phases, characteristic, limiting factors of the environment, adaptability.

\section{МИРОВЫЕ И ОТЕЧЕСТВЕННЫЕ НОВИНКИ И ТЕНДЕНЦИИ В СЕЛЕКЦИИ ИРИСА СИБИРСКОГО}

\author{
Слепченко Н. А., Шошина Е. И.
}

\begin{abstract}
Федеральное государственное бюджетное научное учреждение «Всероссийский научно-исследовательский институт иветоводства и субтропических культур», 2. Сочи, Россия, e-mail: slepchenko@vniisubtrop.ru
\end{abstract}

В последние годы растет интерес к представителям рода Iris, проводится большая работа по созданию новых сортов I. sibirica. Регистрация культиваров ирисов на международном уровне осуществляется Американским обществом ирисоводов (The American Iris Society - AIS). С целью изучения современных тенденций в селекции I. sibirica проведён анализ сортов, зарегистрированных за последние 10 лет (2008-2017 гг.) и опубликованных на сайтах AIS и Госсорткомиссии. В результате установлено, что зарегистрировано 246 сортов, наибольшее количество в 2009 г. - 42 и 2010 г. - 48. Большинство зарегистрированных сортов относятся к группе высокорослых, у 49 \% (120 шт.) заявлена высота 66-85 см. По срокам цветения $60 \%$ сортов относятся к среднецветущим, $24 \%$ - раннецветущие, $16 \%$ - позднецветущие.

Ключевые слова: ирис сибирский, интродукция, коллекция, сорта, мировые новинки, селекция. 
Глава 2. Интродукция и сортоизучение

Род Iris L. (Ирис, Касатик) - один из многочисленных в семействе Iridaceae Juss. Насчитывает большое количество сортов, отличающихся огромным разнообразием. Наибольшее распространение получил, и долгие годы был лидером по популярности, ирис бородатый. В последние годы растёт интерес и к другим представителям этого рода, в особенности к безбородым ирисам, в том числе Iris sibirica L. Сорта I. sibirica интродуцированы и с успехом возделываются в различных регионах нашей страны $[1-3,11]$, в том числе в условиях влажных субтропиков России [5-8, 12, 13].

Благодаря селекционной работе были созданы сорта и гибриды, конкурирующие с совершенством своего родоначальника по размеру, форме и окраске цветка. Сегодня известно около тысячи сортов I. sibirica. Оригинальность селекционных новинок поражает не только изящностью форм, но и окраской долей околоцветника. Изящная форма цветка и листвы, устойчивость к болезням, обильность и продолжительность цветения, значительная выносливость и способность сохраняться на одном месте в течение долгого времени без обновления посадки, а также богатый сортимент оригинальных новинок, - делает их весьма ценными растениями и расширяет применение в декоративных цветочных насаждениях $[9,10]$. Интерес к данной культуре актуален, набирает обороты как у селекционеров, так и у цветоводов и озеленителей [14].

Регистрацию сортов, в том числе и ирисов, в России проводит ФГБУ «Госсорткомиссия» [4]. Ею осуществляются мероприятия по охране и использованию селекционных достижений, собираются и издаются реестры и т. д.

Американское общество ирисоводов - The American Iris Society (AIS) является международной организацией, осуществляющей регистрацию культиваров ирисов на международном уровне $[15,17]$. Сайт организации содержит обширную информацию об ирисах, в том числе современную классификацию, правила и условия регистрации сортов, конкурсах и выставках, а также бюллетени AIS - Irises. Большой раздел Iris Encyclopedia включает базу данных зарегистрированных сортов по группам ирисов, различные тематические блоки (культивирование, награды, семена и др.), материалы о селекционерах [16].

С целью изучения современных тенденций в селекции ириса сибирского проведён анализ сортов, зарегистрированных за последние 10 лет (2008-2017 гг.). Учитывались сорта, включенные в Государственный реестр селекционных достижений, допущенных к использованию [4], а также опубликованные на сайте Американского общества ирисоводов [15]. 
В результате проведённого анализа установлено, что за период с 2008 по 2017 г. было зарегистрировано 246 сортов I. sibirica (табл. 1).

Таблий 1

Общее количество

зарегистрированных сортов Iris sibirica за 2008-2017 гг.

\begin{tabular}{|c|c|c|c|c|c|c|c|c|c|c|c|}
\hline & $\stackrel{\infty}{\stackrel{0}{0}}$ & ஓें & $\stackrel{\circ}{\stackrel{\circ}{\circ}}$ & $\overline{\bar{\nu}}$ & $\stackrel{ }{\vec{N}}$ & $\stackrel{m}{\vec{\nu}}$ & $\stackrel{\nabla}{\vec{N}}$ & $\stackrel{n}{\frac{n}{2}}$ & $\stackrel{0}{\circ}$ & $\overrightarrow{\vec{i}}$ & Всего \\
\hline The American Iris Society & 26 & 42 & 44 & 28 & 25 & 17 & 18 & 19 & 15 & 6 & 240 \\
\hline ФГБУ «Госсорткомиссия» & - & - & 4 & - & - & - & - & - & 1 & 1 & 6 \\
\hline Итого: & 26 & 42 & 48 & 28 & 25 & 17 & 18 & 19 & 16 & 7 & 246 \\
\hline
\end{tabular}

Наибольшее количество культиваров, внесенных в базы было зарегистрировано в 2010 г. - 48 сортов, в том числе 4 Госсорткомиссией, и в 2009 - 42 сорта.

Наибольшее количество сортов, как и авторов, было отмечено в США 147 и 21, соответственно (табл. 2). Далее Польша с 26 сортами и одним автором, Англия - с 24 сортами и 8 авторами. Россия на четвёртом месте с 16 сортами и 2 авторами.

Таблица 2

Количество зарегистрированных сортов Iris sibirica по странам

\begin{tabular}{|c|c|c|}
\hline \multirow{2}{*}{ Страна } & \multicolumn{2}{|c|}{ Количество, um. } \\
\hline & авторов & сортов \\
\hline США & 21 & 147 \\
\hline Польша & 1 & 26 \\
\hline Англия & 8 & 24 \\
\hline Россия & 2 & 16 \\
\hline Чехия & 2 & 13 \\
\hline Германия & 1 & 7 \\
\hline Китай & 2 & 6 \\
\hline Нидерланды & 2 & 3 \\
\hline Литва & 1 & 2 \\
\hline Швейцария & 1 & 1 \\
\hline Новая Зеландия & 1 & 1 \\
\hline Итого: & 42 & 246 \\
\hline
\end{tabular}

Как уже было отмечено, наибольшее количество селекционеров зарегистрировано в США. Здесь же у Marty Schafer and Jan Sacks отмечено наибольшее количество сортов - 58 (рис. 1). У Lech Komarnicki 
Глава 2. Интродукция и сортоизучение

из Польши - 26 сортов за последние 10 лет. На третьем месте Robert Hollingworth (США) с 19 сортами, следом Calvin Helsley (США) с 18. У российского селекционера, зарегистрированного в AIS, Сергея Локтева -10 сортов.

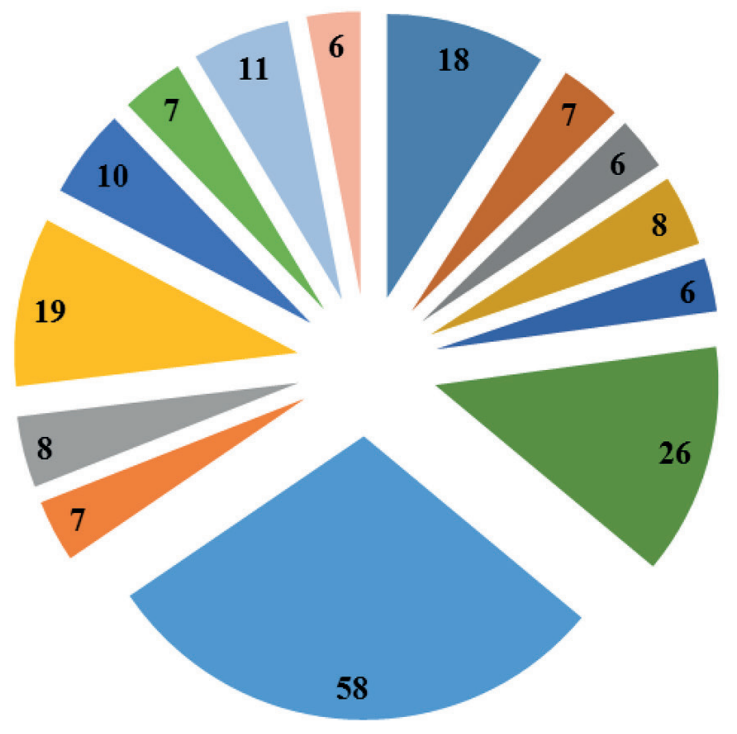

- Calvin Helsley

- Dana Borglum

- Dean Cole

- Jeff Dunlop

- Jennifer Hewitt

- Lech Komarnicki

- Marty Schafer and Jan Sacks

- Neal Pohlman

- Olga Wells

n Robert Hollingworth

- Sergey Loktev

« Tomas Tamberg

$\square$ Zdenek Seidl

- ФГБНУ ФАНЦА

Рис. 1. Некоторые селекционеры Iris sibirica с наибольшим количеством сортов

По сайте AIS и Госсорткомиссии приведены характеристики культиваров ириса, на основании которых сорта были объедены в группы по высоте растений (рис. 2):

- низкорослые (25-50 см) - 17 сортов (7 \%) ('Arthur River Sunrise' (28 cм), 'Gabriel Augustus' (30 cм), 'Too Cute' (33 см), 'Pohlman Glow' (46 см); 'Black Joker' (48 cм));

- среднерослые (51-70 см) - 75 (31 \%) ('Lebedinoye Ozero' ('Лебединое озеро' - 52 см), 'Fiona' (58 cм), 'Petite Purple' (64 cм), 'Karuzela Aniolow' (65 см), 'Dreaming Of You' (66 см), 'Orchid Veil' (69 см);

- высокорослые (более 46 см) - 154 (62\%).

Для удобства и наглядности группу высокорослые разделили еще на 3 подгруппы. Наибольшее количество сортов имеет высоту 71-90 см - 111 шт. (45 \%), в том числе 'Krolowa Nocy' (75 см), 'Zaduma' (80 cм), 'Dance All Night' (84 см); высота растений 91-110 см отмечена у 37 шт. (15\%), в том числе 'Trip To Paris' (92 cм), 'Karmaniola' (95 см), 'Moonstone Marvel' (102 cм), 'Romantycznosc' (107 см) и др. Самых высокорослых (более 111 см) - 6 сортов (2\%), в том числе 'Wielgie' (120 см), 'Tingdie' (126 см), 'Mica Blue' (128 см) и др. 


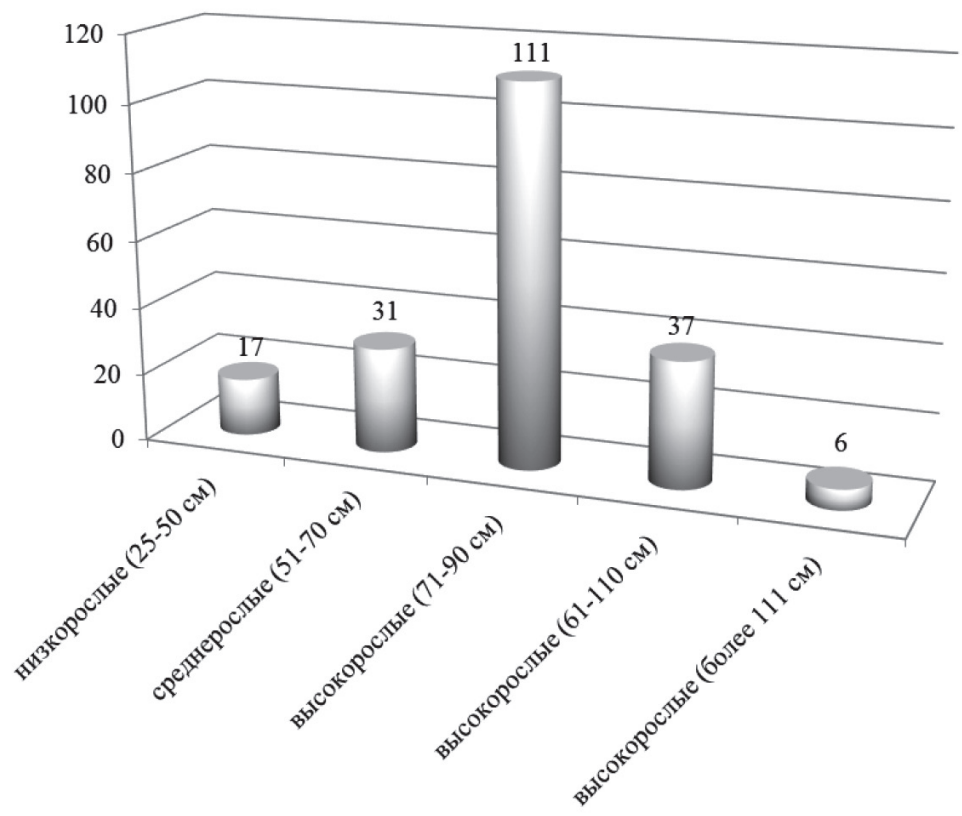

Рис. 2. Количество сортов Iris sibirica, распределённое по срокам цветения, um.

По срокам цветения выделили группы: ранние, средние, поздние.

В первую группу вошли 59 сортов (24 \%) - 'Cream OfTomato', 'Golubaya Laguna' ('Голубая лагуна'), 'Paprikash' и др., в том числе очень ранний 'Count The Ways'. В средней группе насчитывается 147 сорта (60 \%), в том числе раннесредних 6 сортов ('Vilno' ('Вильно'), 'Jerry Murphy', 'Guus' и др.) и среднепоздних - 19 ('Záblesk', 'How Audacious', 'Dash Of Sunlight' и др.). К поздноцветущей группе отнесено 40 сортов (16 \%), в том числе 'Zlate Vlasy', 'Spencer', 'Seeing Red Star', 'Purple Flow' и другие.

Большинство современных сортов с широкими долями околоцветника, есть сорта с почти перекрывающимися фолами, что делает форму цветка более плотной и декоративной. У многих присутствует гофрированный край, иногда с контрастной тонкой полосой. Цветовая гамма богатая - от белых, голубых, сиреневых, синих, фиолетовых оттенков, до розовых, малиновых, красных, коричневых. Существуют одноцветные, двуцветные, а также трёхцветные сорта, что достигается за счёт разных по окраске частей цветка (верхние и нижние доли, стайлы). Последние тенденции - сорта с «тигровой» окраской - широкое, яркое сигнальное пятно и выраженное жилкование.

Таким образом, анализ селекционных новинок Iris sibirica, представленных в базе данных The American Iris Society и Госсорткомиссии за 20082017 гг., показал, что за десять лет было зарегистрировано 246 сортов Iris 
Глава 2. Интродукция и сортоизучение

sibirica, с пиком в 2009 г. - 42 образца и 2010 г. - 48. Наибольшим количеством сортообразцов были представлены сорта американской селекции. Большинство зарегистрированных сортов относятся к группе высокорослых, у 49 \% (120 шт.) заявлена высота 66-85 см. По срокам цветения 60 \% сортов относятся к среднецветущим, $24 \%$ - раннецветущие, $16 \%$ - позднецветущие. Интерес к Iris sibirica возрастает, выводятся новые, интересные сорта, которые могли бы пополнить генофонд института.

\section{Библиографический список}

1. Алексеева Н.Б. Садовая группа «Сибирские ирисы» в Ботаническом саду Петра Великого БИН РАН. Перспективы использования в озеленении // Сборник научных трудов ГНБС. - 2017. - Т. 145. - С. 46-48. - ISSN: 0201-7997.

2. Долганова 3.В. Виды подрода Limniris рода Iris в селекции на повышение генеративной продуктивности сортов // Проблемы ботаники Южной Сибири и Монголии. - 2016. - № 15. - C. 173-183. - ISSN: 2313-3929.

3. Долганова 3.B. Периодичность цветения и особенности размножения Iris L. в условиях лесостепи Алтайского края // Субтропическое и декоративное садоводство. - 2011. - Вып. 45. - С. 114-121. - ISSN: 2225-3068.

4. Сорта культуры "Ирис" // Сорта растений, включённые в Государственный реестр селекционных достижений, допущенных к использованию [Электронный ресурс] - 2018. - 16 июля. - URL: http://reestr.gossort.com/reestr/ culture/369htm (дата обращения: 16.07.2018).

5. Козина В.В. Биологические особенности видовых ирисов в условиях влажных субтропиков России // // Субтропическое и декоративное садоводство. - 2007. - Вып. 40. - C. 83-93. - ISSN: 2225-3068.

6. Козина В.В. Ирис сибирский - перспективная культура для озеленения в зоне влажных субтропиков // Субтропическое и декоративное садоводство. - 2015. - Вып. 54. - C. 40-45. - ISSN: 2225-3068.

7. Козина В.В., Слепченко Н.А. Коллекция ирисов во влажных субтропиках России // Вестник Мичуринского государственного аграрного университета. - 2015. - № 3. - C. 60-67. - ISSN: 1992-2582.

8. Козина В.В., Слепченко Н.А., Клемешова К.В. Ирисы подрода Limniris в условиях сочинского Причерноморья // Новые технологии. - 2017. - № 4. - С. 106-112. - ISSN: 2072-0920.

9. Рындин А. В., Келина А. В., Клемешова К. В. Использование многолетних цветочных культур в зоне влажных субтропиков России // Субтропическое и декоративное садоводство. - 2014. - Вып. 50. - С. 13-20. - ISSN: 2225-3068.

10. Рындин А.В., Келина А.В., Слепченко Н.А., Клемешова К.В. Перспективы импортозамещения в декоративном садоводстве субтропической зоны России // Субтропическое и декоративное садоводство. - 2015. - Вып. 55. - С. 19-26. - ISSN: 2225-3068. 11. Селиверстова Е.Н., Щегринец Н.В. Коллекционный фонд семейства Касатиковых (Iridaceae) в Ставропольском ботаническом саду // Вестник АПК Ставрополья. - 2017. - № 2(26). - C. 194-196. - ISSN: 2222-9345.

12. Слепченко Н.А., Клемешова К.В., Келина А.В. Коллекции цветочно-декоративных культур во Всероссийском научно-исследовательском институте цветоводства и субтропических культур // Цветоводство: история, теория, практика: мат. VII междунар. науч. конф., г. Минск, Беларусь, 24-26 мая 2016 г. - Минск: Конфидо, 2016. - C. 197-199. - ISBN: 978-985-6777-82-3.

13. Слепченко Н.А., Козина В.В., Шошина Е.И. Ирис сибирский в условиях влажных субтропиков России // Проблемы ботаники Южной Сибири и Монголии: материалы 
XVII междунар. науч.-практ. конф. (24-27 мая 2018 г., Барнаул) - Барнаул: Изд-во АлтГУ, 2018. - С. 513-517. - ISSN: 2313-3929.

14. Сорта ирисов // Российское Общество Ириса. [Электронный ресурс] - 2018. 16 июля. - URL: http://ruiris.ru/ Sorta_SIB_Otech_1.htm (дата обращения: 16.07.2018). 15. Iris Classifications // The American Iris Society. [Electronic Resources] - 2018. - 20 июля. - URL: http://www.irises.org/About_Irises/Classifications.html (дата обращения: 20.07.2018). 16. Iris Encyclopedia (SIB) Siberian // The American Iris Society. [Electronic Resources] - 2018. - 20 июля. - URL: http://wiki.irises.org/Sib/WebHome (дата обращения: 20.07.2018).

17. Testované semenáčky SIB kosatců. Siewki SIB irysów pozostawione do obserwacji // Middle-European Iris Society [Electronic Resources] - 2018. - 20 июля. - URL: http:// www.euroiris.net (дата обращения: 20.07.2018).

\title{
WORLD AND DOMESTIC LATEST OFFERS AND TRENDS IN IRIS SIBIRICA BREEDING
}

\author{
Slepchenko N. A., Shoshina Ye. I. \\ Federal State Budgetary Scientific Institution \\ "Russian Research Institute of Floriculture and Subtropical Crops", \\ c. Sochi, Russia, e-mail: slepchenko@vniisubtrop.ru
}

In recent years, the representatives of the genus Iris have been more and more interested; a lot of work has been done to create new cultivars of $I$. sibirica. Registration of iris cultivars at the international level is carried out by the American Iris Society. In order to study modern trends in I. sibirica breeding we analyzed the cultivars registered for the last 10 years (2008-2017) and published on the websites of AIS and the State Commission. As a result, it was found that 246 cultivars were registered, the largest number in $2009-42$ and in $2010-48$. The majority of the registered cultivars belong to the tall-growing group, $49 \%$ (120 pieces) had the height of about $66-85 \mathrm{~cm}$. According to the terms of flowering, $60 \%$ of the cultivars have mediumflowering terms, $24 \%$ - early-flowering terms, and $16 \%$ - late-flowering terms.

Key words: Iris sibirica, introduction, collection, cultivars, world latest offers, breeding.

УДК 634.25:631.527

doi: 10.31360/2225-3068-2018-66-80-86

\section{ИТОГИ ИСПОЛЬЗОВАНИЯ ГЕНОФОНДА ПЕРСИКА ВО ВЛАЖНЫХ СУБТРОПИКАХ РОССИИ}

Смагин Н. Е., Цымбалова А. А.

Федеральное государственное бюджетное научное учреждение «Всероссийский научно-исследовательский институт изветоводства и субтропических культур», 2. Сочи, Россия, e-mail:n_cimb@mail.ru

Показаны результаты сортоизучения 58 сортообразцов персика в коллекции ВНИИЦиСК за период 12 лет (2007-2018 гг.). Обновлён существующий сортимент персика за счёт 10 выделенных перспективных сортов и клонов: сорта - 'Спринголд’, 'Медин Ред’, 'Эрли Блоу', 'Саммерсет', 